Research Paper

\title{
Outcome of Breast Cancer Patients Treated outside of Clinical Trials
}

\author{
Nagi S. El Saghir ${ }^{\bowtie}$, Hussein A. Assi ${ }^{1}$, Sara M. Jaber ${ }^{1}$, Katia E. Khoury ${ }^{1}$, Zahi Nachef ${ }^{1}$, Hana F. Mikdashi1, \\ Nadine S. El-Asmar ${ }^{1}$, Toufic A. Eid ${ }^{2}$ \\ 1. Breast Center of Excellence, Naef K. Basile Cancer Institute and Department of Internal Medicine, American University of Beirut Medical \\ Center, Beirut, Lebanon; \\ 2. Naef K. Basile Cancer Institute and Department of Radiation Oncology, American University of Beirut Medical Center, Beirut, Lebanon.
}

$\square$ Corresponding author: Nagi S. El Saghir, MD, FACP. Professor of Clinical Medicine / Hematology-Oncology, Director, Breast Center of Excellence, Naef K. Basile Cancer Institute, American University of Beirut Medical Center, P.O. Box: 11-0236, Riad El Solh 1107 2020, Beirut Lebanon. Telephone: AUB: +961 1350000 Ext 7489 Fax: AUB: +961 1350000 Ext 7942 Mobile: +961 3827955 Email: nagi.saghir@aub.edu.lb.

(c) Ivyspring International Publisher. This is an open-access article distributed under the terms of the Creative Commons License (http://creativecommons.org/ licenses/by-nc-nd/3.0/). Reproduction is permitted for personal, noncommercial use, provided that the article is in whole, unmodified, and properly cited.

Received: 2014.03.25; Accepted: 2014.05.01; Published: 2014.06.03

\begin{abstract}
Background: Information on outcome of breast cancer patients treated in the community is scarce. Data on outcome of patients treated in real-life clinical practice may provide useful information for performance improvement.

Methods: Study population is from a single institution practice at the American University of Beirut Medical Center. Demographics, clinical characteristics and survival data on patients diagnosed 1997-2010 in two IRB-approved studies were entered and analyzed on SPSS program. Survival was estimated using Kaplan Meier Method.

Findings: Total was 5 I 9 patients. $23.9 \%$ had stage I, $39.7 \%$ stage II, $30.4 \%$ Stage III and $6 \%$ stage IV. ER positive in $74.4 \%$ of patients. $30.6 \%$ of patients $<35$ had TNBC compared to $12.3 \%$ for the whole group. $45.9 \%$ of non-metastatic patients had breast-conserving therapy (BCT). BCT rates increased to $64 \%$ during the second half of the study, coinciding with increasing awareness and changing cultural mores. 5-year and I0-year overall survivals for stage I were $98.9 \%$ and $80.5 \%$, $89.2 \%$ and $70.7 \%$ for stage II, $67.6 \%$ and $35.5 \%$ for stage III, and $39.1 \%$ and $26.1 \%$ for stage IV respectively.

Interpretation: Patients treated outside clinical trials in a multidisciplinary fashion according to guidelines have comparable, and at times better, survival compared to data from trials or population statistics. Locally generated outcome data could be valuable for evaluating results of treatment at individual practices for the purpose of quality assessment and improvement. Our data also provides report of increased rate of breast conserving surgery from Middle East.
\end{abstract}

Key words: breast cancer; outside clinical trials; survival; general oncology practice; breast conserving therapy; mastectomy; triple negative; screening; hormone receptors.

\section{Introduction}

Breast cancer is the most frequent cancer among women in both developed and developing countries. ${ }^{1}$ Approximately 1 out of 8 women will be diagnosed with breast cancer in their lifetime. ${ }^{2}$ Apart from general registry data such as SEER in the USA, National and Regional Registries from industrialized nations, the majority of specific survival data comes from clinical trials. Data on treatment and outcome of patients treated outside of clinical trials remains scarce although it may reflect better what happens in real life patient management and results.

Clinical trials have strict and mandatory diag- 
nostic, management and follow-up protocols. They generate Disease-Free Survival (DFS) and Overall Survival (OS) data at 3 or 5 years with some updates at 8 or 10 years, ${ }^{3-5}$ and provide evidence-based results that are used for clinical practice guidelines. Meta-analyses combine data from clinical trials and present further conclusions on mortality and survival data at 5, 10, 15 years, or even longer. ${ }^{6}$ Population-based data such as SEER Cancer Statistics Review (CSR) provide reports of most recent cancer incidence, mortality, survival, prevalence, and lifetime risk statistics, thus offering a general overview of cancer to the American community on a regular basis. ${ }^{7}$ Outcome data published from major medical centers invariably includes patients who were treated within clinical trials. ${ }^{8}$ Review of data from clinical practice outside of clinical trials can provide direct information on the results of real-life patient management and quality of care. Variable results at different institutions and regions are inevitable for various reasons. Such locally generated outcome data is scarce and if made available, it may provide valuable information for performance and improvement of patients' outcome in real-life clinical practices.

Lebanon has an average of 1700 new breast cancer cases per year. ${ }^{9}$ AUBMC sees an average of 150 patients each year. ${ }^{10}$ In this study, we look at outcome of patients treated uniformly in a single academic practice at AUBMC, which saw about 40 new cases per year, outside of clinical trials, and stratify them by stage and by age groups. We compare our results to those obtained from clinical trials and population statistics. We propose that looking at individual and hospital outcome data may provide, among others, an additional measure of quality of care in clinical practice.

We also provide new information on modern management of breast cancer from the Middle East and optimization of therapy in Low- and MiddleIncome Countries, which coincides with increased awareness, improved medico-surgical expertise, and more available radiation and multimodality therapy. ${ }^{11-13}$

\section{Materials and Methods}

\section{Patients and Data Collection}

Patients diagnosed between 1997 and 2010 were included in two consecutive studies of outcome of breast cancer patients treated outside of clinical trials. All patients were treated uniformly at a single institution practice at the American University of Beirut Medical Center (AUBMC) in Beirut, Lebanon. All patients were included and data was collected from individual patient charts. All laboratory, radiology and pathology reports as well as inpatient and outpatient charts were reviewed. Any patient that overlapped between these two time frames was included only once. Patients who were seen on consultation and treated outside AUBMC were not included. Disease status of patient was documented as alive free of disease, alive with disease, dead or lost to follow up. All deaths were related to breast cancer recurrences. Medical records information included: 1) personal information/demographics including: age at diagnosis and family history of breast cancer; 2) tumor characteristics and disease stage: grade and stage (pathological, clinical, or surgical), tumor size, Estrogen Receptor (ER) status, Progesterone Receptor (PR) status, HER2 receptor status, and lymph node (LN) status; 3) management: surgery, chemotherapy, targeted therapy, radiation therapy, and hormonal therapy.

A total of 519 patients were analyzed. Patients were divided into three age groups: $\leq 35$ years (age group 1), between 35 and 50 years (age group 2), and $\geq 50$ years (age group 3 ).

Pathology was done at AUBMC local laboratory. AUBMC Department of Pathology and Lab Medicine is certified by the College of American Pathologists (CAP); however, in earlier years of the study, FISH test for equivocal HER2 results was done at a commercial central laboratory. Definitions for receptor positivity used were as follows: negative results for Estrogen and Progesterone receptors were based on $<5 \%$ positive staining in all patients. HER2 positivity was defined as strong complete staining of $>10 \%$ of cells, which was changed to $>30 \%$ after the publication of ASCO/ACP guidelines in 2007, or the in the presence of HER2 gene amplification by Fluorescent In Situ Hybridization (FISH) test. Our patients were all diagnosed before our institution switched to the new ASCO/ACP guidelines in 2010. ${ }^{14,15}$

All patients were staged according to AJCC 6. Stage at presentation was used for analysis. Clinical staging (cTNM) was used for all patients who had Neoadjuvant pre-operative therapy. Pathological staging (pTNM) was used for all patients who were operated upfront.

Patients were managed according to international guidelines. Changes were usually rapidly implemented after major publications and oncology meetings such as ASCO, San Antonio Breast Cancer Symposium and St. Gallen Early Breast Cancer Consensus Conference (Example: Adjuvant anti-HER2 therapy was rapidly introduced after ASCO 2005).

No direct comparison with local results from clinical trials was feasible because less than $0.5 \%$ of patients, for various limitations ${ }^{16}$, were entered in clinical trials at AUBMC and in Lebanon. 


\section{Statistical Analysis}

Data was entered and analyzed by SPSS version 18. Analysis of data was performed on our breast cancer patients, stratifying them into three age groups. Frequencies of 14 variables were measured according to univariate analysis for the patients of the three age groups. These included: median age at diagnosis, family history, stage, grade, tumor size, ER status, PR status, HER2 receptor status, triple negativity, LN status, surgery type, radiation therapy, adjuvant chemotherapy, hormonal therapy. Stage IV patients were excluded from the analysis of multimodality therapies that included mastectomy. Bivariate analysis involved the calculation of double-sided p-value for each variable using the Pearson chi square test to assess the significance of this variable distribution among the three age groups. Disease Free Survival was defined as time from date of diagnosis till date of disease recurrence. Overall Survival was defined as time from date of diagnosis till date of death or last follow-up. Although most patients died of breast cancer, some patients died at home and we were unable to confirm the final cause of death and could not compute Breast Cancer Specific Survival rates. 5-year, 8-year, and 10-year overall survival curves stratified by stage were estimated using the Kaplan Meier method. The log-rank p-value was used to compare different groups. In all measurements, a p-value of less than 0.05 was considered significant.

\section{Results}

A total of 519 patients were seen and treated at the single academic practice and were analyzed. Out of those 519 patients analyzed, 124 patients (23.9\%) had stages I disease, 206 patients $(39.7 \%)$ had stage II disease, 158 patients (30.4\%) had stage III disease, and 31 patients $(6 \%)$ had stage IV disease.

Age group 1 included 36 patients $\leq 35$ years with a median age at diagnosis of 32 years, age group 2 included 241 patients between 35-50 years with a median age at diagnosis of 44 years, and age group 3 included 242 patients $\geq 50$ years with a median age of 58 years.

Family history was recorded positive in $25.0 \%$ (9/36), 23.2\% (56/241), and $21.9 \%(53 / 242)$ of the cases in the three consecutive age groups respectively with no statistical significant differences $(p=0.889)$. Patients' clinical characteristics are shown in Table 1.

Table I: Clinical and pathological characteristics in all patients.

\begin{tabular}{|c|c|c|c|c|c|}
\hline Total $=519$ patients & Age(years) & & & & P-value \\
\hline & Group 1 & Group 2 & Group 3 & Overall & \\
\hline & ( $\leq 35$ years $)$ & $(35-50)$ & ( $\geq 50$ years) & & \\
\hline & $(n=36)$ & $(n=241)$ & $(\mathrm{n}=242)$ & $(n=519)$ & \\
\hline Median age (range) & 32 & 44 & 58 & $49(21-85)$ & $\mathrm{N} / \mathrm{A}$ \\
\hline \multicolumn{6}{|l|}{ Stage } \\
\hline Stage I & $5(13.9 \%)$ & $58(24.1 \%)$ & $61(25.2 \%)$ & $124 / 519(23.9 \%)$ & \\
\hline Stage II & $17(47.2 \%)$ & $97(40.2 \%)$ & $92(38.0 \%)$ & $206(39.7 \%)$ & 0.676 \\
\hline Stage III & $13(36.1 \%)$ & $73(30.3 \%)$ & $72(29.8 \%)$ & $158(30.4 \%)$ & \\
\hline Stage IV & $1(2.8 \%)$ & $13(5.4 \%)$ & $17(7.0 \%)$ & $31(6.0 \%)$ & \\
\hline \multicolumn{6}{|l|}{ Tumor size } \\
\hline$\leq 2 \mathrm{~cm}$ & $11(30.6 \%)$ & $97(41.8 \%)$ & $93(41.0 \%)$ & $201 / 495(40.6 \%)$ & 0.087 \\
\hline $2-5 \mathrm{~cm}$ & $14(38.9 \%)$ & $106(45.7 \%)$ & $100(44.1 \%)$ & $220(44.4 \%)$ & \\
\hline$>5 \mathrm{~cm}$ & $11(30.6 \%)$ & $29(12.5 \%)$ & $34(15.0 \%)$ & $74(14.9 \%)$ & \\
\hline \multicolumn{6}{|l|}{ LN status } \\
\hline No & $11(32.4 \%)$ & $96(41.7 \%)$ & $97(44.1 \%)$ & $204 / 484(42.1 \%)$ & \\
\hline N1 & $15(44.1 \%)$ & $74(32.2 \%)$ & $67(30.5 \%)$ & $156(32.2 \%)$ & \\
\hline N2 & $5(14.7 \%)$ & $40(17.4 \%)$ & $31(14.1 \%)$ & $76(15.7 \%)$ & \\
\hline N3 & $3(8.8 \%)$ & $20(8.7 \%)$ & $25(11.4 \%)$ & $48(9.9 \%)$ & 0.631 \\
\hline \multicolumn{6}{|l|}{ Grade } \\
\hline Grade I & $2(6.7 \%)$ & $31(17.4 \%)$ & $20(12.3 \%)$ & $53 / 370(14.3 \%)$ & 0.06 \\
\hline Grade II & $11(36.7 \%)$ & $80(44.9 \%)$ & $88(54.3 \%)$ & $179(48.4 \%)$ & \\
\hline Grade III & $17(56.7 \%)$ & $67(37.6 \%)$ & $54(33.3 \%)$ & $138(37.3 \%)$ & \\
\hline \multicolumn{6}{|l|}{ ER } \\
\hline Positive & $21(58.3 \%)$ & $167(70.8 \%)$ & $187(80.6 \%)$ & $375 / 504(74.4 \%)$ & $0.004^{*}$ \\
\hline \multicolumn{6}{|l|}{ PR } \\
\hline Positive & $19(52.8 \%)$ & $164(69.5 \%)$ & $166(71.6 \%)$ & $349 / 504(69.2 \%)$ & 0.075 \\
\hline \multicolumn{6}{|l|}{ HER2 } \\
\hline Positive & $9(26.5 \%)$ & $58(26.0 \%)$ & $47(21.3 \%)$ & $114 / 478(23.8 \%)$ & 0.469 \\
\hline TNBC & $11(30.6 \%)$ & $31(13.4 \%)$ & $19(8.3 \%)$ & $61 / 496(12.3 \%)$ & $0.001^{*}$ \\
\hline
\end{tabular}

Abbreviations: LN, lymph node; N/A, not applicable; ER, estrogen receptor; PR, progesterone receptor; HER2, human epidermal growth factor receptor; TNBC, triple negative breast cancer. 
Information about tumor histological characteristics (grade, estrogen, progesterone, and HER2 receptors) is also summarized in Table 1. ER was positive in $58.3 \%$ of very young patients ( $\leq 35$ years), whereas ER positivity was seen in $70.8 \%$ and $80.6 \%$ of patients between 35-50 years and $\geq 50$ years, respectively, with a significant $p$-value $=0.004$. HER2 receptors were positive in $23.8 \%$ of all patients. Differences in PR and HER2 status between the three age groups were not statistically significant.

TNBC represented $12.3 \%$ of all patients; the percentage of TNBC was highest in the very young age group at $30.6 \%$, whereas it was $13.4 \%$ and $8.3 \%$ in the age group 2 and 3 , respectively, with a p-value of $=0.001$.

All patients with non-metastatic breast cancer were managed with multidisciplinary approach as summarized in Table 2.

Neoadjuvant therapy was given to 52 patients representing $32 \%$ of LABC cases. Adjuvant hormonal therapy was given to patients with ER-positive and/or PR-positive tumors.

Table 2: Treatment modalities in patients with non-metastatic breast cancer.

\begin{tabular}{|c|c|c|c|c|c|}
\hline \multirow{3}{*}{$\begin{array}{l}\text { Total=488 pa- } \\
\text { tients }\end{array}$} & \multicolumn{4}{|c|}{ Age(years) } & \multirow[t]{3}{*}{ P-value } \\
\hline & Group 1 & Group 2 & Group 3 & Overall & \\
\hline & ( $\leq 35$ years) & $(35-50)$ & ( $\geq 50$ years) & & \\
\hline \multicolumn{6}{|l|}{ Surgery } \\
\hline No surgery & $0(0 \%)$ & $3(1.3 \%)$ & $5(2.2 \%)$ & $8 / 488(1.6 \%)$ & 0.799 \\
\hline $\mathrm{BCT}$ & $19(54.3 \%)$ & 107(46.9\%) & $98(43.6 \%)$ & $224(45.9 \%)$ & \\
\hline Mastectomy & $16(45.7 \%)$ & $118(51.8 \%)$ & $122(54.2 \%)$ & $256(52.5 \%)$ & \\
\hline \multicolumn{6}{|c|}{$\begin{array}{l}\text { Adjuvant chem- } \\
\text { otherapy }\end{array}$} \\
\hline Yes & $32(91.4 \%)$ & 192(88.1\%) & 168(79.6\%) & $392 / 464(84.5 \%)$ & $0.027^{*}$ \\
\hline \multicolumn{6}{|l|}{$\begin{array}{l}\text { Adjuvant hor- } \\
\text { monal therapy }\end{array}$} \\
\hline Yes & $25(80.6 \%)$ & 173(89.6\%) & 182(91.0\%) & $380 / 424(89.6 \%)$ & 0.213 \\
\hline \multicolumn{6}{|c|}{$\begin{array}{l}\text { Radiation ther- } \\
\text { apy }\end{array}$} \\
\hline Yes & $28(90.3 \%)$ & 191(92.7\%) & $158(87.3 \%)$ & $377 / 418(90.2 \%)$ & 0.201 \\
\hline
\end{tabular}

Abbreviations: BCT, breast conserving therapy.

Breast conservation therapy (BCT) was done at an overall rate of $45.9 \%$ in the non-metastatic breast cancer population, with $54.3 \%$ in patients $\leq 35$ years, $46.9 \%$ in patients between $35-50$ years, and $43.6 \%$ in patients $\geq 50$ years. $91.4 \%$ of patients $\leq 35$ years and $88.1 \%$ of patients $35-50$ years received adjuvant chemotherapy, while $79.6 \%$ of patients $\geq 50$ years did so, with a statistically significant $p$-value $=0.027$. Both hormonal and radiation therapy did not differ significantly between age groups. Hormonal therapy was given to $80.6 \%, 89.6 \%$ and $91.0 \%$ of the patients in the three age groups, respectively. Radiation therapy was given to $90.3 \%, 92.7 \%$ and $87.3 \%$ of patients in the three age groups, respectively. As for trastuzumab targeted therapy which was recommended in $2005^{17,18}$, it was given to $90.7 \%$ (49 out of 54 ) of patients with HER2-positive tumors. Separate analysis for HER2-overexpressive or TNBC subtypes was not performed because of smaller numbers in those subgroups.

A temporal comparison of the rates of mastectomies and BCTs was performed in early breast cancer patients. During the second half of the study, which coincided with increasing awareness campaigns in Lebanon, the rate of breast conserving Therapy (BCT) has increased from $48.8 \%$ in the first half of the studied interval period (before 2002, inclusive) to $64.4 \%$ after the year 2002 .

Table 3: Rates of mastectomies and BCTs in early stage breast cancer.

\begin{tabular}{lllll}
\hline Total=323 patients & \multicolumn{3}{c}{ Year of diagnosis } & P-value \\
\cline { 2 - 4 } & $\begin{array}{l}\text { Before 2002 } \\
\text { (inclusive) }\end{array}$ & After 2002 & Overall & \\
\hline Surgery & & & & \\
BCT & $63(48.8 \%)$ & $125(64.4 \%)$ & $188 / 323(58.2 \%)$ & $0.005^{*}$ \\
Mastectomy & $66(51.2 \%)$ & $69(35.6 \%)$ & $135(41.8 \%)$ & \\
\hline
\end{tabular}

Abbreviations: BCT, breast conserving therapy.

Survival: 5-year, 8-year, and 10-year Overall-Survival (OS) stratified according to age and stage are shown in Figure 1(a-d) and Figure 2(a-d). Overall, patients with stage I had a survival rate of $98.9 \%$ at 5 years, $96.6 \%$ at 8 years, and $80.5 \%$ at 10 years; patients with stage II had rates of $89.2 \%, 87.9 \%$ and $70.7 \%$; patients with stage III had rates of $67.6 \%, 43.4 \%$ and $35.5 \%$; while those with stage IV has survival rates of $39.1 \%, 26.1 \%$ and $26.1 \%$ at 5,8 and 10 years respectively.

When we looked at survival rates by age groups, Stage I patients had survival rates up to $100 \%$ at 5 years and lowest at $71 \%$ at 10 years. Stage II patients had 5 -year survival rates of $70.7 \%$ for $\leq 35$ years, $94.2 \%$ for $35-50$ years, and $88.2 \%$ for $\geq 50$ years, and 10 -year survival rates between $84.8 \%$ for $35-50$ years, and $71.2 \%$ for $\geq 50$ years. Stage III patients had 5 -year survival rates of $62.9 \%$ for $\leq 35$ years, $73.4 \%$ for $35-50$ years, and $62.3 \%$ for $\geq 50$ years, which became $62.9 \%$, $50.5 \%$ and $31.8 \%$ at 8 years respectively, and $62.9 \%$, $30.3 \%$, and $31.8 \%$ at 10 years respectively. Interestingly, of 13 patients between 35-50 years with stage IV disease, survival rates of $56.6 \%$ at 5 years and $37.7 \%$ at both 8 and 10 years were observed. Moreover, of 17 patients $\geq 50$ years with stage IV disease, $28.1 \%$ survived at 5 years and continued through 10 years. The number of patients with metastatic breast cancer were too small at look at Progression Free Survival. 


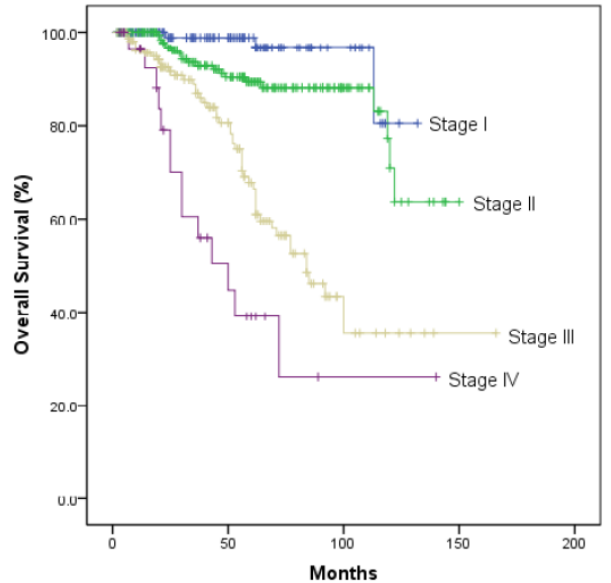

(a)

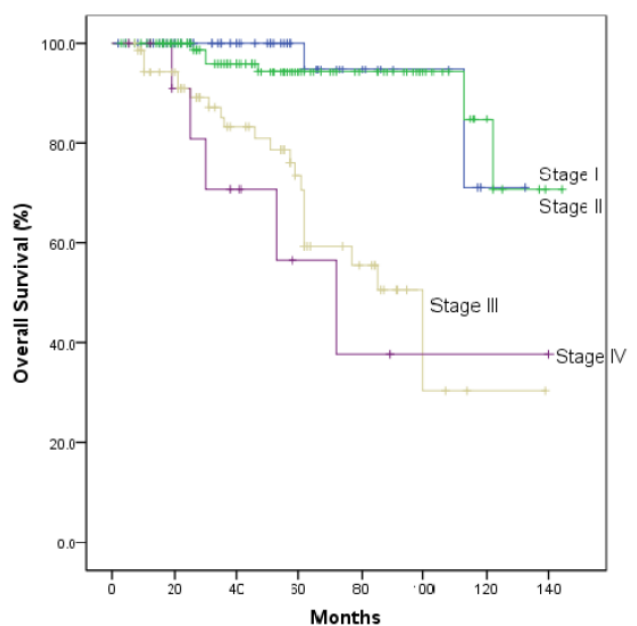

(c)

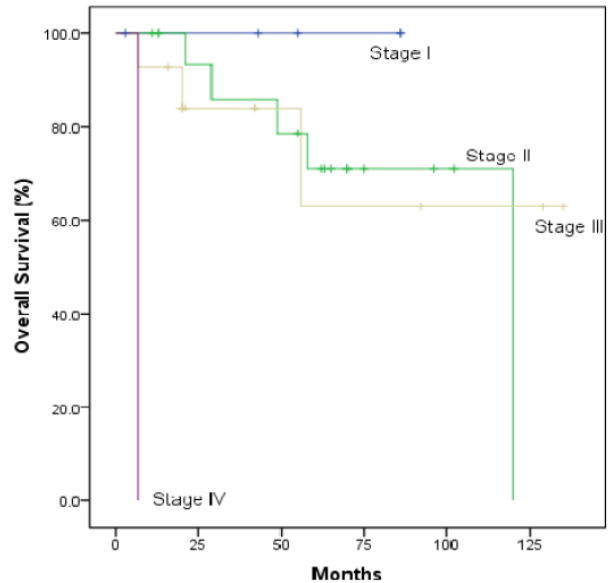

(b)

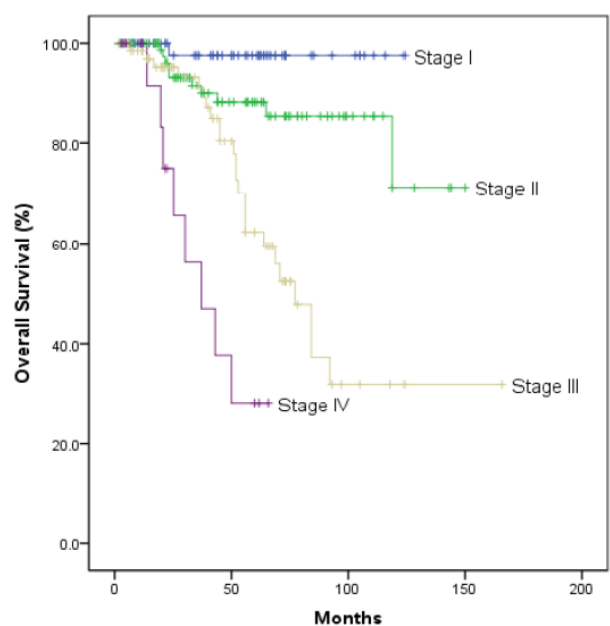

(d)

Figure I. Overall Survival curve of breast cancer patients stratified by stage for (a) all patients; (b) patients $\leq 35 y$ rs; (c) patients between 35-50yrs; (d) patients $\geq 50 y$ rs.
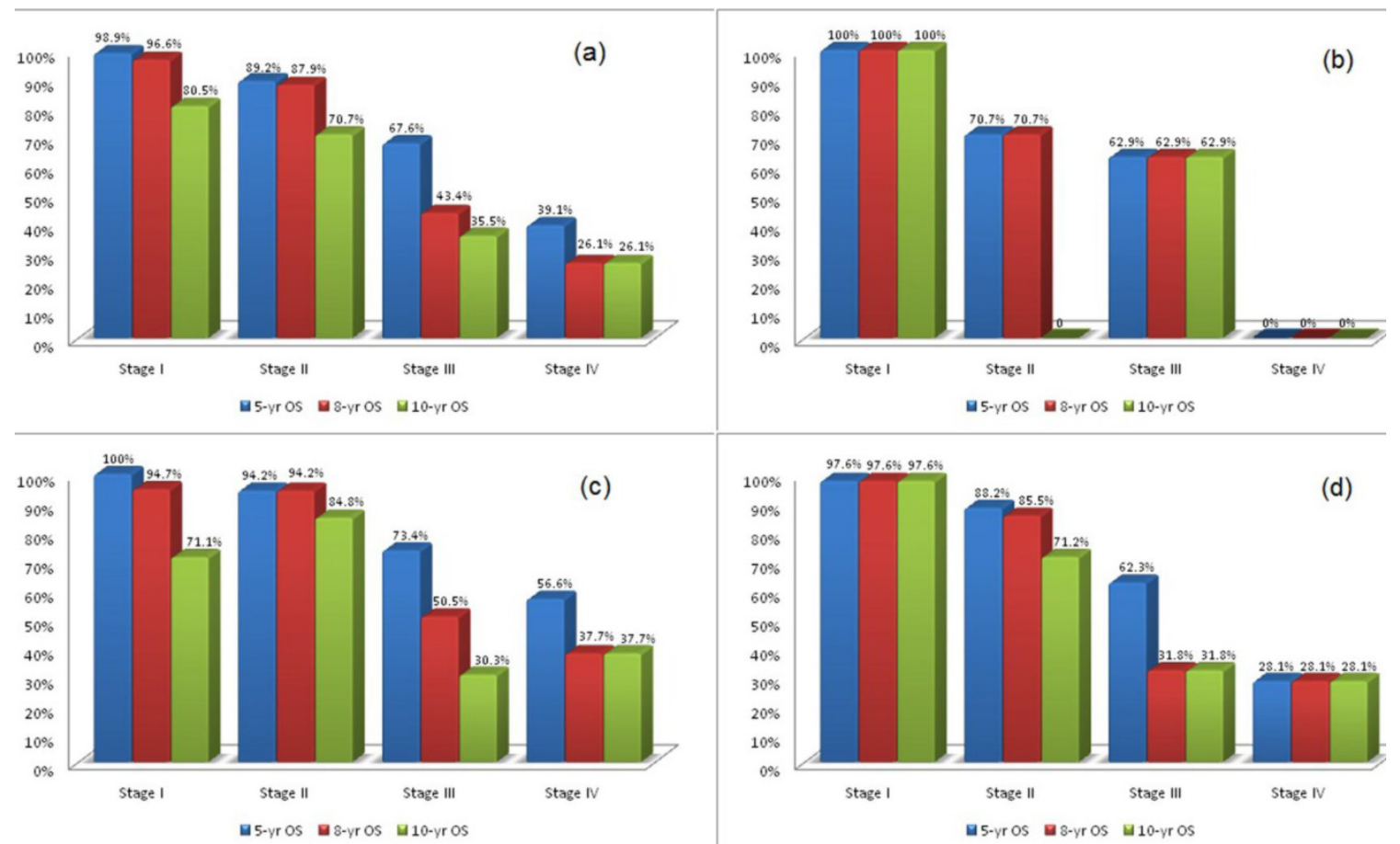

Figure 2. 5-year, 8-year, 10-year survival of patients stratified by stage for (a) all patients; (b) patients $\leq 35$ yrs; (c) patients between 35-50yrs; (d) patients $\geq 50 y r s$. 
We proceeded with multivariate Cox proportional hazards analysis where we stratified patients by stage, ER status and age and looked at effects of ER-positivity and age on overall survival. Table 4 shows survival based on stage while controlling for age and ER status as predictors of survival. ER-positivity conferred better survival with a low hazard ratio $(\mathrm{HR}=0.420)$ for the overall patient population.

We also performed univariate analysis looking at the effects of age on survival for each stage separately. Results, presented in Table 5, show that age was a predictor of survival for stage II ( $p$-value $=0.015$ ) where patients $\leq 35$ years had a worse prognosis. A Cox regression multivariate analysis was then fitted for each of stages II and III to look at the role of age while controlling for ER-positivity (that of stages I and IV could not be fitted due to low number of patients). Results, in Tables 6 and 7, show that age was a predictor of worse survival in patients $\leq 35$ years in stage II patients only $(\mathrm{HR}=4.926$ for patients $\leq$ 35 years compared to patients $35-50$ years, and $\mathrm{HR}=2.19$ for patients $\leq 35$ years compared to patients $\geq 50$ years). Age was not a predictor of survival in patients $\leq 35$ years in stage III ( $\mathrm{p}$-value $>0.05$ ).

Table 4: Cox regression analysis of patients stratified by age, stage and ER status.

\begin{tabular}{|c|c|c|}
\hline Parameter & Hazard Ratio & P-value \\
\hline Stage & & $<0.001^{*}$ \\
\hline I & & $<0.001^{*}$ \\
\hline II & 2.994 & 0.076 \\
\hline III & 12.674 & $<0.001^{*}$ \\
\hline IV & 29.800 & $<0.001^{*}$ \\
\hline ER positivity & 0.420 & $<0.001^{*}$ \\
\hline Age & & $>0.05$ \\
\hline$\leq 35 \mathrm{yrs}$ & & 0.166 \\
\hline $35-50 \mathrm{yrs}$ & 0.634 & 0.234 \\
\hline$\geq 50 \mathrm{yrs}$ & 0.955 & 0.904 \\
\hline
\end{tabular}

Table 5: Survival of patients stratified by stage and age.

\begin{tabular}{llllll}
\hline & & $\leq 35$ yrs & $35-50$ & $\geq 50$ yrs & P-value \\
\hline All patients & $\mathrm{n}$ & 36 & 241 & 242 & 0.322 \\
& 5 -yr OS & $69.3 \%$ & $86.7 \%$ & $78.4 \%$ & \\
& 8 -yr OS & $69.3 \%$ & $76.1 \%$ & $66.2 \%$ & \\
\multirow{5}{*}{ Stage I } & 10 -yr OS & $46.2 \%$ & $62.0 \%$ & $58.9 \%$ & \\
& $\mathrm{n}$ & 5 & 58 & 61 & 0.859 \\
& 5 -yr OS & $100 \%$ & $100 \%$ & $97.6 \%$ & \\
& 8 -yr OS & $100 \%$ & $94.7 \%$ & $97.6 \%$ & \\
\multirow{5}{*}{ Stage II } & 10 -yr OS & $100 \%$ & $71.1 \%$ & $97.6 \%$ & \\
& $\mathrm{n}$ & 17 & 97 & 92 & 0.015 \\
& 5 -yr OS & $70.7 \%$ & $94.2 \%$ & $88.2 \%$ & \\
& 8 -yr OS & $70.7 \%$ & $94.2 \%$ & $85.5 \%$ & \\
Stage III & 10 -yr OS & $0 \%{ }^{*}$ & $84.8 \%$ & $71.2 \%$ & \\
& $\mathrm{n}$ & 13 & 73 & 72 & 0.793 \\
& 5 -yr OS & $62.9 \%$ & $73.4 \%$ & $62.3 \%$ & \\
& 8 -yr OS & $62.9 \%$ & $50.5 \%$ & $31.8 \%$ & \\
Stage IV & 10 -yr OS & $62.9 \%$ & $30.3 \%$ & $31.8 \%$ & \\
& $\mathrm{n}$ & 1 & 13 & 17 & $<0.001^{*}$ \\
& 5 -yr OS & $0 \%$ & $56.6 \%$ & $28.1 \%$ & \\
& 8 -yr OS & $0 \%$ & $37.7 \%$ & $28.1 \%$ & \\
& 10 -yr OS & $0 \%$ & $37.7 \%$ & $28.1 \%$ & \\
\hline
\end{tabular}

Table 6: Cox regression analysis of stage II patients stratified by age and ER status.

\begin{tabular}{|c|c|c|}
\hline Parameter & Hazard Ratio & P-value \\
\hline ER positivity & 0.501 & 0.121 \\
\hline Age & & - \\
\hline$\leq 35 \mathrm{yrs}$ & & 0.033 \\
\hline $35-50 \mathrm{yrs}$ & 0.203 & 0.009 \\
\hline$\geq 50$ yrs & 0.456 & 0.162 \\
\hline
\end{tabular}

Table 7: Cox regression analysis of stage III patients stratified by age and ER status.

\begin{tabular}{|c|c|c|}
\hline Parameter & Hazard Ratio & P-value \\
\hline ER positivity & 0.312 & $<0.001^{*}$ \\
\hline Age & & $>0.05$ \\
\hline$\leq 35 \mathrm{yrs}$ & & 0.249 \\
\hline $35-50 \mathrm{yrs}$ & 1.330 & 0.644 \\
\hline$\geq 50 \mathrm{yrs}$ & 2.105 & 0.238 \\
\hline
\end{tabular}

\section{Discussion}

We report the results of characteristics and outcome of patients with early and advanced stage breast cancer treated with multimodality therapy outside of clinical trials. We report improved survival rates and also a positive impact of screening campaigns on staging, surgical management and improved survival rates with the application of modern therapy from a developing country. Demographic and patient clinical characteristics show that the median age of all our patients is 49 years, which is consistent with our earlier observations. ${ }^{13,19,20}$ This is also in line of reports from other Middle Eastern / $\mathrm{LMCs}^{21}$ that show a younger median age at presentation of patients with breast cancer that differs from data of industrialized nations. This subject has been discussed extensively elsewhere.11,16,22 Twenty-two percent of our patients had a positive family history of breast cancer. Young age and positive family history emphasize the importance of performing genetic mutation studies in our population. ${ }^{23}$

We report that the majority of patients had positive receptors with $74.4 \%$ having ER positivity and $69.2 \%$ having PR positivity. HER2 receptors were overexpressed in $23.8 \%$ of all patients. As for Triple Negative Breast Cancer, an overall rate of $12.3 \%$ was observed, which is consistent with general literature estimates. ${ }^{24}$ However, TNBC was noted in $30 \%$ of patients below the age of 35 years, which raises the possibility of association with BRCA1 mutations and the need for genetic study of those patients. ${ }^{24}$

As for survival of breast cancer patients, we report survival rates that are comparable, and at times, even better than clinical trials and population data. In patients with stage I breast disease, the 5-year overall survival was $98.9 \%$, which is similar to the rate of 98.4\% reported in SEER. ${ }^{2}$ If we look at patients with 
stage II and III breast cancer, the 5 -year OS is $89.2 \%$ and $67.6 \%$, compared to $83.9 \%$ reported in SEER for breast cancer with spread to regional lymph nodes. As for metastatic breast cancer, although our numbers are small, the 5-year OS (39.1\%) appears to be even higher than that reported in SEER for example $(23.8 \%) .^{2}$ While confirming that ER-positivity conferred better survival for the overall patient population, multivariate Cox proportional hazards analysis, while controlling for ER-positivity, showed that young age was a predictor of survival for stage II where patients $\leq 35$ years had a worse prognosis.

Our results also have an additional value coming from low and middle income countries. We provide new data on characteristics and outcome of young patients with breast cancer in developing countries. Relatively favorable outcomes in Lebanon, classified as a Middle Income country by WHO, are encouraging and reflect in part advances in therapy, especially also that young age was noted to have a negative prognostic influence in an earlier study from our institution. ${ }^{25,26}$ We report a significant decrease in the rates of mastectomy and a corresponding rise in Breast Conserving Therapy in patients with early stage breast cancer throughout the years. In fact, analysis of our data showed that the rate of BCT increased from $48.4 \%$ between $1997-2002$ to $64.4 \%$ between 2002 and 2010, with a corresponding decrease in total mastectomy rate from $51.2 \%$ to $35.6 \%$. The year 2002 coincides with the time when widespread media breast cancer awareness campaigns were initiated in Lebanon. ${ }^{27,28}$ This trend may also reflect changing cultural mores, patients' increasing demands for breast conservation, surgical expertise and radiation therapy availability. This is an encouraging positive trend in the Middle East and LMCs where mastectomy rates were rather much higher at $65-88 \%$. 13,29-31

\section{Conclusion}

In conclusion, multidisciplinary therapy of breast cancer patients outside of clinical trials, according to clinical trial results and consensus guidelines, shows very good survival rates at 5 and 10 years for early stage disease; however, stage III patients continues to decline from $67.6 \%$ at 5 years to $35.5 \%$ at 10 years. Survival of patients with stage IV is rather encouraging with rates of $39.1 \%$ at 5 years and $26.1 \%$ at 10 years. Those results compare favorably to those reported from clinical trials and population data and are an additional indication of the positive effects of modern therapy. We also report a direct observation of a positive trend towards more breast-conserving therapy in the Middle East and Low- and Middle Income Countries.
In addition to general population statistics, locally generated data may be a useful guide for performance improvement, and even could be useful for accreditation and privileging. Centers that have outcome results below average survivals achieved in clinical trials may have to be asked to look for potential causes, and implement ways to improve their results; the studies of outcome of rectal surgery at Scandinavian hospitals and how it led to recommendations for privileging of hospitals and surgeons are an example ${ }^{32}$.

\section{Acknowledgements}

The authors wish to thank all members of the departments of surgery, pathology, radiology, and radiation oncology at the American University of Beirut Medical Center who contributed to the care of patients of the study.

\section{Funding Source}

Funding for this study was provided by an unrestricted grant from Sanofi Oncology.

\section{Ethical approval}

The study was approved by the Institutional Review Board (IRB) at the American University of Beirut Medical Center.

\section{Competing interests}

The authors have declared that no competing interest exists.

\section{References}

1. Ferlay J, Shin H-R, Bray F, et al. Estimates of worldwide burden of cancer in 2008: GLOBOCAN 2008. Int J Cancer. 2010;127(12):2893-917.

2. [Internet] National Cancer Institute. Cancer of the Breast - SEER Stat Fact Sheets. http://seer.cancer.gov/statfacts/html/breast.html

3. Mackey JR, Martin M, Pienkowski T, et al. Adjuvant docetaxel, doxorubicin, and cyclophosphamide in node-positive breast cancer: 10-year follow-up of the phase 3 randomised BCIRG 001 trial. Lancet Oncol. 2012;14(1):72-80.

4. Gianni L, Dafni U, Gelber RD, et al. Treatment with trastuzumab for 1 year after adjuvant chemotherapy in patients with HER2-positive early breast cancer: a 4-year follow-up of a randomised controlled trial. Lancet Oncol. 2011;12(3):236-44.

5. Krag DN, Anderson SJ, Julian TB, et al. Sentinel-lymph-node resection compared with conventional axillary-lymph-node dissection in clinically node-negative patients with breast cancer: overall survival findings from the NSABP B-32 randomised phase 3 trial. Lancet Oncol. 2010;11(10):927-33.

6. Peto R, Davies C, Godwin J, et al. Comparisons between different polychemo-therapy regimens for early breast cancer: meta-analyses of long-term outcome among 100,000 women in 123 randomised trials. Lancet. 2012;379(9814):432-44.

7. [Internet] National Cancer Institute. SEER Cancer Statistics Review 1975-2009. http://seer.cancer.gov/csr/1975_2009_pops09/index.html.

8. Hernandez-Aya LF, Chavez-Macgregor M, Lei X, et al. Nodal status and clinical outcomes in a large cohort of patients with triple-negative breast cancer. J Clin Oncol. 2011;29(19):2628-34.

9. [Internet] National Cancer Registry. Cancer in Lebanon 2003. 2003. http://www.moph.gov.lb/Publications/Documents/NCR2003.pdf.

10. Alameddine R, El Saghir N, Elias E, et al. Effects of Nodal Status and Extent of Surgery on Survival in Triple Negative Breast Cancer. J Can Res Updates. 2013;2.

11. Anderson BO, Cazap E, El Saghir NS, et al. Optimisation of breast cancer management in low-resource and middle-resource countries: executive summary of the Breast Health Global Initiative consensus, 2010. Lancet Oncol. 2011;12(4):387-98.

12. Chopra R. The Indian scene. J Clin Oncol. 2001;19(18 Suppl):106S-111S 
13. El Saghir NS, Khalil MK, Eid T, et al. Trends in epidemiology and management of breast cancer in developing Arab countries: a literature and registry analysis. Int J Surg. 2007;5(4):225-33.

14. Hammond MEH, Hayes DF, Dowsett M, et al. American Society of Clinical Oncology/College Of American Pathologists guideline recommendations for immunohistochemical testing of estrogen and progesterone receptors in breast cancer. J Clin Oncol. 2010;28(16):2784-95.

15. Wolff AC, Hammond MEH, Schwartz JN, et al. American Society of Clinical Oncology/College of American Pathologists guideline recommendations for human epidermal growth factor receptor 2 testing in breast cancer. Arch Pathol Lab Med. 2007;131(1):18-43.

16. El Saghir NS. Modern cancer management and research in the Middle East. Lancet Oncol. 2012;13(11):1076-8.

17. Piccart-Gebhart MJ, Procter M, Leyland-Jones B, et al. Trastuzumab after adjuvant chemotherapy in HER2-positive breast cancer. $\mathrm{N}$ Engl J Med. 2005;353(16):1659-72.

18. Romond EH, Perez EA, Bryant J, et al. Trastuzumab plus adjuvant chemotherapy for operable HER2-positive breast cancer. $N$ Engl J Med. 2005;353(16):1673-84.

19. El Saghir NS, Shamseddine AI, Geara F, et al. Age distribution of breast cancer in Lebanon: increased percentages and age adjusted incidence rates of younger-aged groups at presentation. J Med Liban. 2002;50(1-2):3-9.

20. El Saghir NS, Shamseddine A, Geara F, et al. Breast cancer in Lebanon. Increased age-adjusted incidence rates in younger-aged groups at presentation: implications for screening and for Arab-American ethnic groups. Ethn Dis. 2005;15(1 Suppl 1):11-2.

21. Najjar H, Easson A. Age at diagnosis of breast cancer in Arab nations. Int J Surg. 2010;8(6):448-52.

22. Harford JB, Otero I V, Anderson BO, et al. Problem solving for breast health care delivery in low and middle resource countries (LMCs): consensus statement from the Breast Health Global Initiative. Breast. 2011;20 Suppl 2:S20-9.

23. [Internet] American University of Beirut. News - AUBMC team receives $\$ 250,000$ grant to investigate the causes of breast cancer in Lebanon. http://www.aub.edu.lb/news/Pages/ breast-cancer-grant.aspx.

24. Lee LJ, Alexander B, Schnitt SJ, et al. Clinical outcome of triple negative breast cancer in BRCA1 mutation carriers and noncarriers. Cancer. 2011;117(14):3093-100.

25. El Saghir NS, Seoud M, Khalil MK, et al. Effects of young age at presentation on survival in breast cancer. BMC cancer. 2006;6:194

26. Assi HA, Khoury KE, Dbouk H, et al. Epidemiology and prognosis of breast cancer in young women. J Thorac Dis. 2013;5(Suppl 1):S2-8.

27. Adib SM, Sabbah MA, Hlais S, et al. Research in action: mammography utilization following breast cancer awareness campaigns in Lebanon 2002-05. East Mediterr Health J. 2009;15(1):6-18.

28. Adib SM, El Saghir NS, Ammar W. Guidelines for breast cancer screening in Lebanon Public Health Communication. J Med Liban. 2009;57(2):72-4.

29. El Saghir NS, Eniu A, Carlson RW, et al. Locally advanced breast cancer: treatment guideline implementation with particular attention to low- and middle-income countries. Cancer. 2008;113(8 Suppl):2315-24.

30. El Saghir NS, Adebamowo CA, Anderson BO, et al. Breast cancer management in low resource countries (LRCs): consensus statement from the Breast Health Global Initiative. Breast. 2011;20 (Suppl 2):3-11.

31. El Saghir NS, Anderson BO. Breast cancer early detection and resources: where in the world do we start? Breast. 2012;21(4):423-5.

32. Holm $\mathrm{T}$, Johansson $\mathrm{H}$, Cedermark $\mathrm{B}$, et al. Influence of hospital- and surgeon-related factors on outcome after treatment of rectal cancer with or without preoperative radiotherapy. Br J Surg. 1997;84(5):657-63.

\section{Author Biography}

Nagi S. El Saghir, MD, FACP, Professor and Director, Breast Center of Excellence, Naef K. Basile Cancer Institute, American University of Beirut Medical Center, Beirut, Lebanon. His research and activities are focused on breast cancer and young women and he is widely published in numerous peer-reviewed journals. He served on Panels for International Guidelines for the management of breast cancer including Breast Health Global Initiative (BHGI), Advanced Breast Cancer (ABC1 \& ABC2) and adapted NCCN-MENA guidelines. He also serves as Journals' regular peer reviewer and editorial board member. He is author of "ABC of Breast Diseases" 2013 in Arabic Language, as well as Awareness Booklet "Knowledge Road Map to Cure". He has received many awards including Lebanese President's
Medal of Honor, LSMO, LOP, Cairo University, Lebanese League for Woman's Rights. Dr. Nagi El Saghir graduated from Free University of Brussels, Belgium, trained at The Brooklyn Hospital-State University of New York, and St. Luke's Roosevelt Hospital Center-Columbia University College of Physicians \& Surgeons in New York. He served on many Committees, Panels and Research Groups including ASCO, ESMO, EORTC Breast Cancer Group, EASO, AMAAC, and ASCO. He is Founding-President of the Lebanese Society of Medical Oncology (LSMO), President of The Lebanese Breast Cancer Foundation (LBCF) and Chair of ASCO International Affairs Committee (2013-2014).

Toufic A. Eid, MD, is a graduate of the Lebanese University. He completed two years of residency training in Internal Medicine at the Lebanese University, followed by five years of residency training and one year of fellowship in Radiation Oncology at the American University of Beirut Medical Center, Beirut, Lebanon. He is currently an Assistant Professor in Radiation Oncology at the American University of Beirut Medical Center. 